\title{
Effects of land use intensity on the natural attenuation capacity of urban soils in Beijing, China
}

\author{
Meie Wang ${ }^{\mathrm{a}}$, Jack H. Faber ${ }^{\mathrm{b}}$, Weiping Chen ${ }^{\mathrm{a}, *}$, Xiaoma $\mathrm{Li}^{\mathrm{a}}{ }^{\mathrm{a}}$, Bernd Markert ${ }^{\mathrm{c}}$ \\ a State Key Laboratory of Urban and Regional Ecology, Research Centre for Eco-environmental Sciences, Chinese Academy of Sciences, Beijing 100085, China \\ ${ }^{\mathrm{b}}$ Alterra, Wageningen UR, PO Box 47, 6800 AA Wageningen, The Netherlands

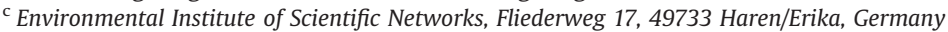

\section{A R T I C L E I N F O}

\section{Article history:}

Received 11 August 2014

Received in revised form 17 March 2015

Accepted 18 March 2015

Available online 1 April 2015

Keywords:

Urban expansion

Ecosystem service

Urban contaminated soil

Natural attenuation

Soil quality mapping

\begin{abstract}
A B S T R A C T
Urban soils are major sinks that provide the services of attenuating and detoxifying environmental pollutants. This significant ecosystem service of urban soil can be evaluated by the natural attenuation capacity (NAC). In this research, we develop a method to calculate the natural pollutant attenuation capacity of urban soils on the basis of 5 chemical and physical measurements. By selecting municipal parks soils for reference, we assessed the spatial and temporal changes of NAC in Beijing city soils under influences of rapid urbanization. Results indicated that NAC was increasingly impacted by land use in the order: parks $<$ schools $<$ woods $<$ residential areas $<$ traffic areas. Sealed area rate and construction age are two main factors affecting the urban soil NAC. However, their roles are opposite. It would take dozens of years to reach the maximum soil NAC by soil self-recovery. The spatial distribution of NAC in Beijing built-up area resembled the age of urbanization. Regional hot spots of NAC corresponded to the land use distribution and the urbanization progress in Beijing city. The developed index can be used to assess the impacts of urbanization on soil ecosystem services of natural attenuation of contaminants.
\end{abstract}

(c) 2015 Elsevier Inc. All rights reserved.

\section{Introduction}

Worldwide, the urban population has reached $52 \%$ and is expected to rise at $0.5-0.87 \%$ per year for the next 50 years. China is in the midst of an incredibly rapid process of urbanization. Shanghai, Beijing and Guangzhou are amongst the 10 most densely populated metropolis of the world. Energy and resource consumptions and waste and pollutant emissions are intense in urban areas (Pataki et al., 2011). The urbanization processes drastically affect the indigenous soil ecological template (Kaye et al., 2006; Pavao-Zuckerman, 2008).

The risks of environmental harms associated with depositions of urban pollutants may be indicated by the extent of ecosystem services (Faber and Wensem, 2012; Galic et al., 2012; Nienstedt et al., 2012; Pataki et al., 2011; Thomsen et al., 2012). Ecosystem services benefit men gain from their habitat, including benefits of providing provisions, regulations, and cultural stimulations and auxiliary services that compliment the primary eco-functions (Millennium Ecosystem Assessment, 2005). Urban soils are major sinks that provide the services of attenuating and detoxifying environmental pollutants (Dominati et al., 2010;NRC, 2000).

\footnotetext{
* Corresponding author. Fax: +8616284 3981.

E-mail address: wpchen@rcees.ac.cn (W. Chen).
}

Soils possess the ability to reduce the mass, toxicity, mobility, volume, and/or concentration of incoming pollutants. This ability is deployed through reactions of biodegrading, dispersing, adsorbing, diluting, volatilizing, stabilizing, and transforming the soil borne pollutants (US Environmental Protection Agency; EPA, 1999). The significance of a reaction is dependent on properties of soils and the nature of pollutants. Van Wijnen et al. (2012) articulated the natural attenuation capacity (NAC) of soils with respect to their ability to biodegrade organic contaminants. The resulting model included multiplying effects of 3 microbial indicators, i.e. functional microbial activity, potential carbon mineralization rate, and potential mineralization rate of organic nitrogen, and 3 abiotic indicators, i.e. soil organic matter content, soil $\mathrm{pH}$, and phosphorus content as proxy indicators (Van Wijnen et al., 2012).

Identifying proper pollutants and employing appropriate metrics would be challenging for assessing natural pollutant attenuation capacities of urban soils as they undergo changes due to rapid urbanization, and there are many pollutants and potential indicators for natural pollutant attenuation capability of soils (van Wijnen et al., 2012). In China, heavy metals and polyaromatic hydrocarbons (PAHs) are the most persistent pollutants in the urban areas. Therefore, the soil's filtering and immobilizing reactions are more relevant than the degrading and destructing reactions in deciding the soil attenuation capacities. The 
concentrations of soluble heavy metal and PAHs in soils might be correlated to solid-solution dissociation constant, $K_{d}$, which in turn were functions of organic matter content, clay content, and $\mathrm{pH}$ of soils (Sauve et al., 2000). In this regard, the soils' pH and organic matter and clay contents would be the appropriate metrics to assessing natural pollutant attenuation capacity of urban soils.

In this research, we developed a method to calculate the natural attenuation capacity of urban soils by modifying the ecosystem-service performance index proposed by Rutgers et al. (2008) and Van Wijnen et al. (2012). Proper soil property parameters and reference values were selected to evaluate the impacts of urbanization on the NAC of urban soils. Beijing is used as a case to illustrate spatial and temporal changes of NAC in soils across the city with respect to the attributes of urbanization.

\section{Methods and materials}

\subsection{Calculation of natural attenuation capacity}

The ecosystem services are not well defined quantitatively (Luck et al., 2009; van Wijnen et al., 2012). Rutgers et al. (2008) and Van Wijnen et al. (2012) calculated the ecosystem-service performance index (EPX) of soil using the following equation:

$\mathrm{EPX}=10^{-}\left[\frac{+\log \left|\left(\frac{\mathrm{VAR}_{o b s}^{i}}{\operatorname{VAR}_{\text {ref }}^{i}}\right)\right|+\cdots-\log \left|\left(\frac{\operatorname{VAR}_{o b s}^{j}}{\operatorname{VAR}_{\text {ref }}^{j}}\right)\right|}{n}\right]$

where $\operatorname{VAR}^{i \ldots j}$ are soil parameters from $i$ to $j$ that contribute to EPX of soils. Subscripts obs and ref denote the parameter's observed and reference values, respectively (Rutgers et al., 2008). The symbol $n$ denotes number of parameters in the computation. Generally, 4-6 parameters with the highest scores were selected among a group. The reference values represent a "maximum ecological potential", which could be brought forward by independent measurements and/or evaluations by professional panels.

For the natural attenuation capacity (NAC) of urban soils, we selected 5 soil property parameters (Table 1 ) that may determine the fate of heavy metals and PAHs in soils, namely soil organic carbon content (SOC), clay content (Clay), bulk density (BD), $\mathrm{pH}$ measured in pore water $(\mathrm{pH})$, and total soil $\mathrm{N}$ contents (TN). The soil total $\mathrm{N}$ content was included as a supplemental parameter to clay and organic carbon contents of soils (Hassink, 1997). For biodegradation of organic pollutants (Eq. (1)), the contributing parameters had multiplying or dividing effects toward ecosystemservice performance index (EPX). The soil's capacity to react with or attenuate heavy metals and PAHs are additive in nature. It is the sum of surface reaction sites in [soil organic matters + clays + organic N]. In addition, the capacities are also susceptible to the multiplying/dividing influences of the soil's $\mathrm{pH}$ and bulk density that respectively adjust the attenuation capacity up and down and account for the net soil mass per unit volume. Eq. (1) was modified accordingly to obtain the natural pollutant attenuation capacity of urban soils (NAC):

$\mathrm{NAC}=10\left[\frac{\log \left(\frac{\mathrm{SOC}}{\mathrm{SOG}_{\text {ref }}}+\frac{\text { Clay }}{\text { Clayref }}+\frac{\mathrm{TN}}{\mathrm{TN}_{\text {ref }}}\right)+\log \left(\frac{\mathrm{pH}}{\mathrm{pH} \mathrm{H}_{\text {ref }}}\right)-\log \left(\frac{\mathrm{BD}}{\mathrm{BD}_{\text {ref }}}\right)}{3}\right]$

In the above equation, the variables had all been defined. They represent the key soil parameters under the current land use. The variables with subscript ref refer to the reference value representing the parameters when the NAC of the soil is at its optimal. We used the arithmetic average of soils obtained at the public parks in Beijing for the reference values per reasoning in van Wijnen et al. (2012).

\subsection{Study area and soil sampling}

Beijing as a human habitat dates back for more than 3000 years. The built-up area now covers about $700 \mathrm{~km}^{2}$. Starting from the city center, the city expands over time and outward and is encircled by 5 concentric ring roads, the traffic thorough fares. The urbanization began from the central area inside the 2nd ring road, then sequentially toward the north, west, east and south directions (Fig. 1).

Soils were sampled according to a 1 min latitude $\times 1$ min longitude (approximately $1.9 \mathrm{~km} \times 1.0 \mathrm{~km}$ ) grid. One composite sample was obtained inside a $500 \mathrm{~m} \times 500 \mathrm{~m}$ representative landscape of each grid. In this manner, two hundred thirty three $0-10 \mathrm{~cm}$ surface soil samples were collected. Each sample was composed of 5 subsamples of the four corners and the center point in a $10 \mathrm{~m} \times 10 \mathrm{~m}$ square. Among them, 25 were from public parks, 58 from traffic areas, 53 from schoolyards and public areas, 28 from agricultural and wooded area (excluding parks), and 69 from residential areas (Fig. 1). These habitats were chosen based on the dominated landscape in each grid.

\subsection{Measurements of soil parameter and paved area}

Soil parameters were determined as described in Wang et al. (2011), Wang et al. (2012) and Peng et al. (2011). Soil organic carbon contents were determined using $\mathrm{HCl}$ treated method (Nam et al., 2008). Briefly, soil samples were treated with $1 \mathrm{M} \mathrm{HCl}$ for $24 \mathrm{~h}$ to decompose carbonate associated carbon. And then, the treated soil was dried at $60{ }^{\circ} \mathrm{C}$ before determination of carbon content by an elemental analyzer (Elementar, Hanau Germany). Soil $\mathrm{pH}$ was determined in distilled water at a soil-to-solution ratio of $1: 2.5$. Surface soil $(0-10 \mathrm{~cm})$ bulk density was determined using stainless cutting rings $\left(100 \mathrm{~cm}^{3}\right)$. The ring soil samples were dried at $105^{\circ} \mathrm{C}$ for $24 \mathrm{~h}$ to calculate bulk density. Five repeats were sampled for each $10 \mathrm{~m} \times 10 \mathrm{~m}$. Clay content was determined using a laser particle size analyzer and calculated according to the USDA soil classification scheme. Total nitrogen content was measured using an elemental analyzer (Elementar, Hanau Germany).

The percentage of impervious paved area of the $500 \mathrm{~m} \times 500 \mathrm{~m}$ sampling grids was identified using GIS Arcgis 9.3.

Table 1

Key soil parameters used in NAC calculation, their ranges and ecological processes involved.

\begin{tabular}{|c|c|c|}
\hline Soil parameters & Range & Ecological process involved \\
\hline Soil organic carbon content (SOC) (\%) & $0.241-5.11$ & Adsorption of heavy metals and PAHs in soils and degradation of PAHs \\
\hline Clay content (Clay) (\%) & $2.51-17.7$ & Adsorption of heavy metals in soils \\
\hline Bulk density (BD) $\left(\mathrm{g} / \mathrm{cm}^{3}\right)$ & $0.968-1.77$ & Leaching of heavy metals and PAHs \\
\hline $\mathrm{pH}$ measured in pore water $(\mathrm{pH})$ & $7.06-8.4$ & Adsorption of heavy metals and biodegradation of PAHs \\
\hline Total soil N contents (TN) (\%) & $0.031-0.205$ & Supplemental parameter to clay and organic carbon contents of soils \\
\hline
\end{tabular}




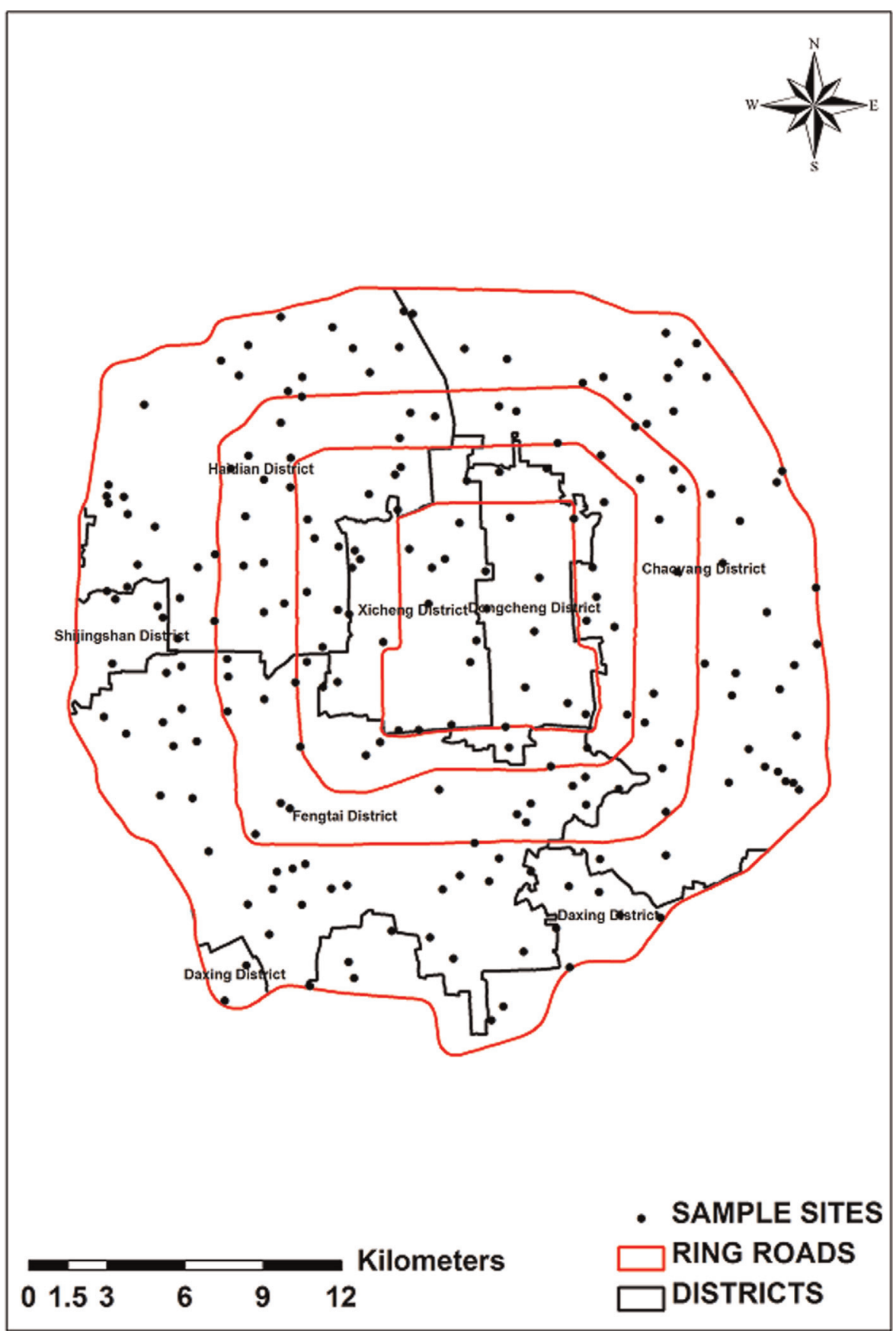

Fig. 1. The spatial distribution of sample sites in the built-area of Beijing city.

\subsection{Data analysis and mapping}

Spearman and Pearson correlation analysis and post-hoc multiple comparisons were conducted using SPSS (PASW Statistics 18.0). SigmaPlot 12.0 was used for plot and regression analysis. The spatial distribution of NAC was mapped using ordinary kriging interpolation techniques in Arcgis 9.3. Hotspots of NAC were identified using local Moran's I. "Regional hotspots" (high values in high value neighborhood) and "cool spots" (low values in low value neighborhood) were marked. All raw data was standardized before further analyses by statistics and GIS.

\section{Results and discussion}

\subsection{Spatial factors affecting natural attenuation capacity}

The natural pollutant attenuation capacities of soils inside Beijing in descending order are parks $>$ schools $>$ wooded areas $>$ residential areas $>$ traffic areas (Fig. 2). Those of the residential and traffic areas were significantly lower than those in the parks. The soils in the residential and traffic areas were more susceptible to physical disturbances and anthropogenic activities than soils in the parks and schools (Pouyat et al., 2002). Spearman correlation analysis showed that NAC in traffic areas exhibited a negative significant nonlinear correlation with the sampling location's distance to city center $\left(r^{2}=-0.373\right)$, the closer to city center the higher of soil NAC was. The urban areas away from the 


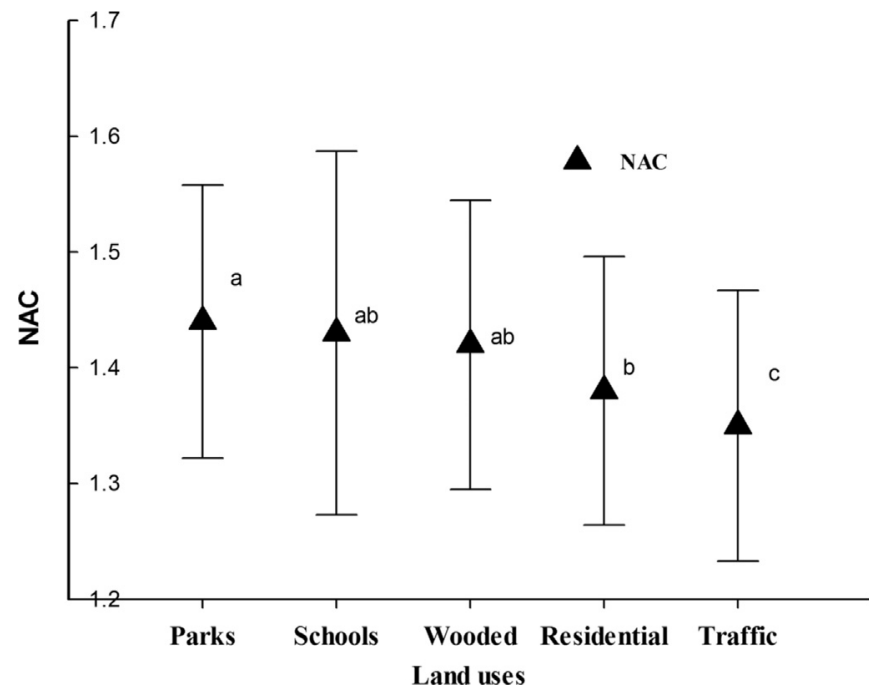

Fig. 2. Natural pollutant attenuation capacity of urban soils of different land uses in Beijing. Values reported (mean \pm S.D.) are of the dimensionless parameter in reference to the optimal capacity. Relatively higher value denotes greater capacity.

city center would experience more frequent disturbances in terms of urbanization and have shorter time to recover from it. The NAC versus distance correlations were not significant for soils of the parks and residential areas because parks and residential areas are evenly distributed across inside the 5th ring road, i.e. the entire developed area.

The relative size of the paved surface showed significant negative impacts to NAC of soils in the parks (Table 2) in which the soil's NAC decreased with increasing relative paved surface according to a linear function relationship:

$\mathrm{NAC}=1.596-0.231 x, \quad(0 \leq x \leq 1), \quad R^{2}=0.204$

where $x$ represent the paved surface (\%).

Contrary, the NAC of soils in the roadside traffic area was significantly positive correlated the relative size of the paved surface, while the NAC of soils in residential area was not significantly impacted by the pavement (Table 2). Compared to the parks, the traffic and residential areas always contained high percentages of paved surfaces. From NAC of soils in the parks to NAC of soils in traffic areas represented the two extremes of how did pavements in urban area impact the soil's natural pollutant attenuation capacities (Fig. 2).

\subsection{Temporal changes in natural attenuation capacity}

Urbanization in Beijing has a temporal gradient that depicts how long ago (in years) did the location become urbanized. We labeled this time horizon "construction age" and accordingly every sampling grid was assigned a construction age. The NAC of soils in

Table 2

Spearman correlation coefficients for soil NAC as related to distance from city center, ages and sealed area rate around sampling site.

\begin{tabular}{llll}
\hline Urban development factor & \multicolumn{2}{l}{ Land use } & \\
\cline { 2 - 4 } & Parks & Traffic & Residential \\
\hline Distance to city center (km) & -0.286 & $-0.373^{*}$ & -0.017 \\
Percent paved surface area (\%) & $-0.405^{*}$ & $0.328^{*}$ & 0.112 \\
Construction age (year) & $0.701^{* *}$ & - & $0.366^{* * *}$ \\
\hline
\end{tabular}

- Denotes the absence of data.

* Significance at 0.05 level.

** Significance at 0.01 level. parks and residential areas significantly increase with the constructing age (Table 2). Following the urbanization, the soils needed time to recover from the initial disruptions. Gradually, the physical, chemical and biological properties of the soils would stabilize into a new equilibrium with the surroundings (Scharenbroch et al., 2005). We were unable to establish the temporal gradients for the traffic areas. However, we noted that the NAC of soils in the traffic areas covered a wide range and we expected they would exhibit the same trend as the park and residential areas (Fig. 2).

To explore the temporal changes of NAC in urban soils, we used the residential areas that composed of a 1-50 year temporal gradient and the park area that composed of a 1-800 year temporal gradient for further elaborations. The NAC of soils in the parks and residential areas increased with construction age according to the exponential function relationships (Fig. 3A). For park area

$\mathrm{NAC}=1.577-0.262 e^{-0.013 t}, \quad R^{2}=0.417$

For residential area

$\mathrm{NAC}=1.45-0.193 e^{-0.144 t}, \quad R^{2}=0.159$

where $t$ represents the construction age in years.

Two NAC temporal gradients of different time horizons and different urban land uses yielded different outcomes. However, it was clear, the natural pollutant attenuation capacity of urban soils would grow, become stabilized, and approach a maxima. It was suggested the maximum and initial soil NAC in parks was slightly higher than that in residential area. The rate of soil NAC increases for residential soils, $r=0.144$, was considerably higher than that of the park area, $r=0.013$. Derivations for Eqs. (4) and (5) suggested that $t=16$ was the demarcation. When $t<16$, the soil NAC of residential areas increased faster than those in the park areas. When $t>16$, the results were the opposite. The soil NAC of residential areas took approximately 20 years to reach the maximal plateau while that of the park areas would need about 200 years to do the same (Fig. 3B).

Using the soils of the park areas as the example, the temporal gradient and paved surfaces were significant factors in determining the soil NAC, explained 41.7 and $20.4 \%$ of the variances of NAC in urban soils, respectively. Other inherent soil properties and spatial elements might have affected the NAC (Pouyat et al., 2002; Raciti et al., 2011).

\subsection{Spatial distribution of the natural attenuation capacity}

The natural attenuation capacities of urban soils in Beijing were spatially coded and grouped into low, middle and high NAC zones (Fig. 4). The low NAC zone was located in the south-west quadrant of the city, while the high NACs zone was found toward the city center and the north-east-south expansion. The footprint of the high NAC zone overlapped the areas that were earliest in undergoing urbanization, while the low NAC zone was found to cover the more recently urbanized city quarters.

In terms of regional distributions, there were NAC hot and cool spots throughout. The hot spots were isolated high NAC locations inside the high NAC zone and the cool spots were isolated low NAC locations inside of the low NAC zone. Regionally, the hot spots were found exclusively in the north half the city between the 2nd and 5th roads where parks, university campuses, and old residential neighborhoods are located, in other words they represented the long time horizons in urbanization. The regional cool spots were distributed in the south between the 4th and 5th ring roads where majority of the new developments are located. This distribution corresponds to the land use distribution and the urbanization progress in Beijing. 

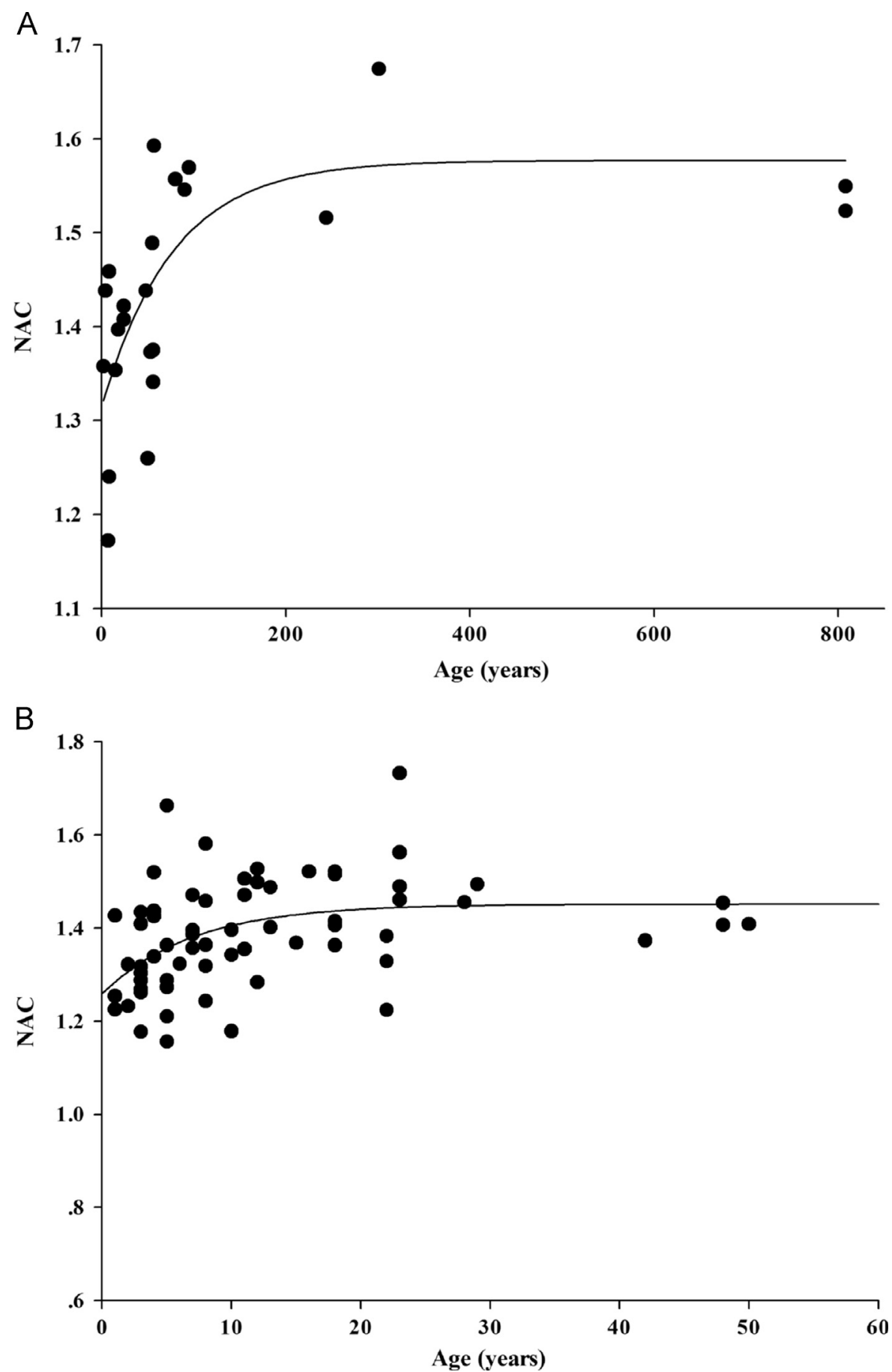

Fig. 3. Exponential function relationships between soil NAC in parks (A) and residential areas (B) and the construction age.

\section{Conclusions}

Natural attenuation of contaminants by urban soils is an important ecosystem service to protect the human population and other sensitive receptors from hazardous exposure. Urbanization may disturb the natural soil template and the capacity to mitigate forthcoming environmental risks. Our results suggested the following:

1. The natural pollutant attenuation capacity of the soil would be decimated during the course of urbanization. It would gradually recover, become stabilized over time, and eventually approached a maximum.
2. In Beijing, soils in public parks showed the highest natural pollutant attention capacities in comparison to other urban land uses, such as residential and traffic areas.

3. The natural pollutant attenuation capacities of soil in the traffic area throughout the city are inversely correlated to location's distance to city center through nonlinear functions and the natural pollutant attenuation capacities of soil in public parks were inversely correlated to the location's percentage of paved surfaces and how long ago the location becoming urbanized in nonlinear functions.

4. The spatial distribution of natural pollutant attention capacities in Beijing coincided with the city's pattern of urban development. Footprint of high capacities of natural pollutant 


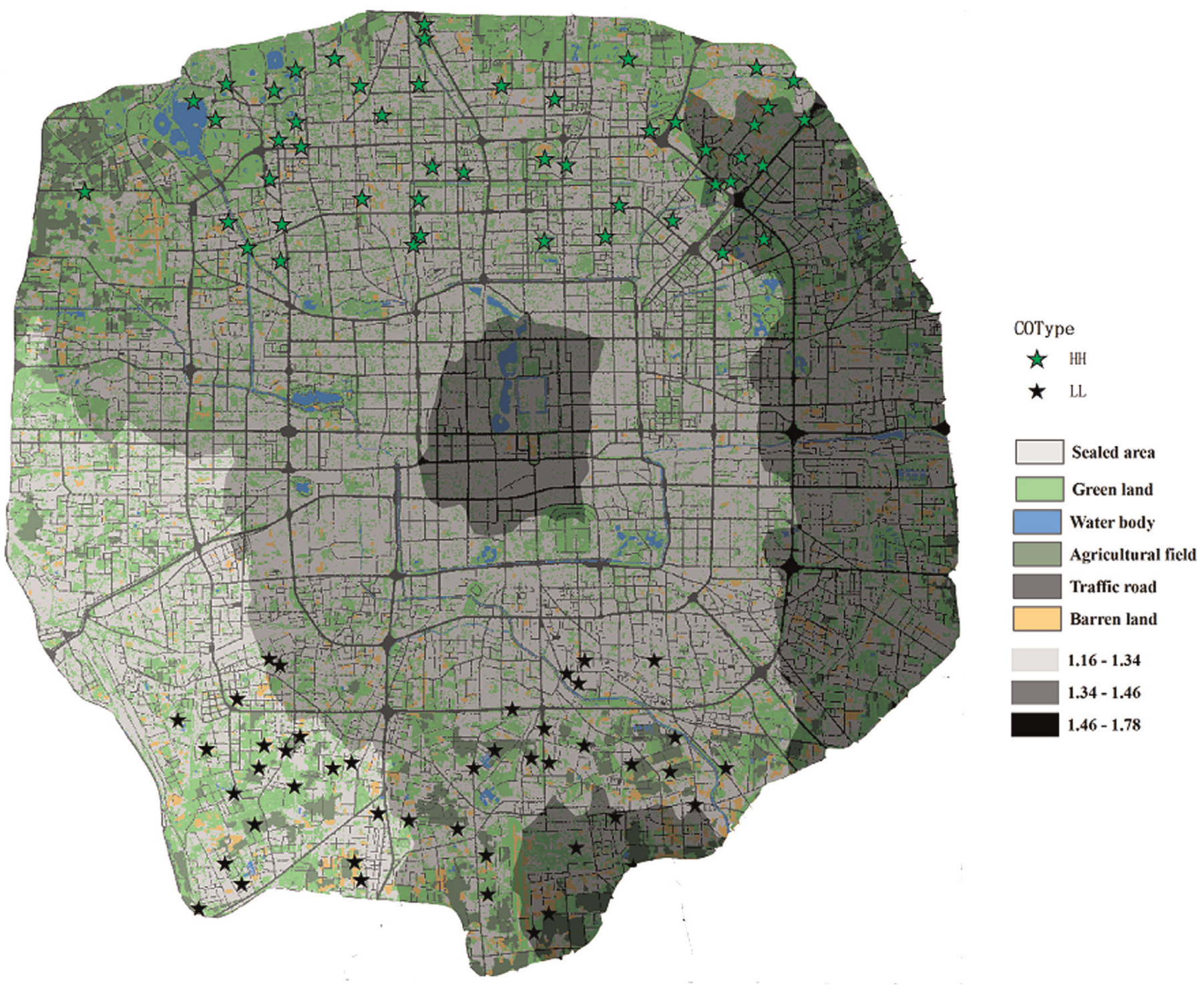

Fig. 4. Spatial distribution maps of soils' natural attenuation capacity in Beijing city.

attenuation zone overlapped with areas of the earliest in undergoing urban development. Soils with low capacity of natural pollutant attention cover the most recently developed of the city.

\section{Acknowledgments}

We gratefully acknowledged financial supports provided by the National Natural Science Foundation of China (Grant nos. 41030744 and 41271503) and the Special Foundation of State Key Lab of Urban and Regional Ecology (Grant no. SKLURE2013-1-04).

\section{References}

Dominati, E., Patterson, M., Mackay, A., 2010. A framework for classifying and quantifying the natural capital and ecosystem services of soils. Ecol. Econ. 69, 1858-1868.

EPA, 1999. In: Use of monitored natural attenuation at superfund, RCRA corrective action, and underground storage of tank sites. U.S. Environmental Protection Agency, Office of Solid Waste and Emergency Response, pp 4-17. 〈http://www. epa.gov/swerust1/directiv/d9200417.pdf (accessed November 2013).
Faber, J.H., Wensem, J.V., 2012. Elaborations on the use of the ecosystem services concept for application in ecological risk assessment for soils. Sci. Total Environ. $415,3-8$.

Galic, N., Schmolke, A., Forbes, V., Baveco, H., van den Brink, P.J., 2012. The role of ecological models in linking ecological risk assessment to ecosystem services in agroecosystems. Sci. Total Environ. 415, 93-100.

Hassink, J., 1997. The capacity of soils to preserve organic C and $\mathrm{N}$ by their association with clay and silt particles. Plant Soil 191, 77-87.

Kaye, J.P., Groffman, P.M., Grimm, N.B., Baker, L.A., Pouyat, R.V., 2006. A distinct urban biogeochemistry? Trends Ecol. Evol. 21 (4), 192-199.

Luck, G.W., Harrington, R., Hrrison, P.A., Kremen, C., Berry, P.M., 2009. Quantifying the contribution of oranisms to the provision of ecosystem services. Bioscience 59, 223-225.

Millennium Ecosystem Assessment, 2005. Ecosystem and Human Well-Being: Synthesis. World Resource Institute, Washington, DC.

Nam, J.J., Thomas, G.O., Jaward, F.M., Steinnes, E., Gustafsson, O., Jones, K.C., 2008 PAHs in background soils feom Western Europe: influence of atmospheric deposition and soil organic matter. Chemosphere 70, 1596-1602.

National Research Council, 2000. Natural Attenuation for Groundwater Remediation. National Academy Press, Washington, DC, USA.

Nienstedt, K.M., Brock, T.C.M., van Wensem, J., Montforts, M., Hart, A., 2012. Development of a framework based on an ecosystem services approach for deriving specific protection goals for environmental risk assessment of pesticides. Sci. Total Environ. 415, 31-38.

Pataki, D.E Carreiro, M.M. Cherrier, J., Grulke, N.E. Jennings, V., 2011. Coupling biogeochemical cycles in urban environments: ecosystem services, green solutions, and misconceptions. Front. Ecol. Environ. 9 (1), 27-36.

Pavao-Zuckerman, M.A., 2008. The nature of urban soils and their role in ecologica restoration in cities. Rest. Ecol. 16 (4), 642-649. 
Peng, C., Chen, W., Liao, X., Wang, M., Ouyang, Z., Jiao, W., 2011. Polycyclic aromatic hydrocarbons in urban soils of Beijing: status, sources, distribution and potential risk. Environ. Pollut. 159 (3), 802-808.

Pouyat, R., Groffman, P., Yesilonis, I., Hernandez, L., 2002. Soil carbon pools and fluxes in urban ecosystems. Environ. Pollut. 116, S107-S118.

Raciti, S.M., Groffman, P.M., Jenkins, J.C., Pouyat, R.V., Fahey, T.J., 2011. Accumulation of carbon and nitrogen in residential soils with different land-use histories. Ecosystems 14, 287-297.

Rutgers, M., Mulder, C., Schouten, A.J., Bloem, J., Bogte, J.J., Breure, A.M., Brussaard L., de Goede, R.G.M., Faber, J.H., Jagers op Akkerhuis, G.A.J.M., Keidel, H., Korthals, G.W., Smeding, F.W., ten Berg, C., van Eekeren, N., 2008. Soil Ecosystem Profiling in the Netherlands with Ten References for Biological Soil Quality. RIVM 75 76. Report 607604009.

Sauve, S., Hendershot, W., Allen, H., 2000. Solid-solution partitioning of metals in contaminated soils: dependence on $\mathrm{pH}$, total metal burden, and organic matter. Environ. Sci. Technol. 34 (7), 1125-1131.
Scharenbroch, B.C., Lloyd, J.E., Johnson-Maynard, J.L., 2005. Distinguishing urban soils with physical, chemical and biological properties. Pedobiologia 49, 283-296.

Thomsen, M., Faber, J.H., Sorensen, P.B., 2012. Soil ecosystem health and servicesevaluation of ecological indicators susceptible to chemical stressors. Ecol. Indic. $16,67-75$.

van Wijnen, H.J., Rutgers, M., Schouten, A.J., Mulder, C., de Zwart, D., Breure, A.M., 2012. How to calculate the spatial distribution of ecosystem services-natural attenuation as example from The Netherlands. Sci. Total Environ. 415, 49-55.

Wang, M., Bai, Y., Chen, W., Markert, B., Peng, C., Ouyang, Z., 2012. A GIS technology based potential eco-risk assessment of metals in urban soils in Beijing, China. Environ. Pollut. 161, 235-242.

Wang, M., Peng, C., Chen, W., Ouyang, Z., 2011. Microbial biomass carbon and enzyme activities of urban soils in Beijing. Environ. Sci. Pollut. Res. 18, 958-967. 